Check for updates

Cite this: RSC Adv., 2017, 7, 46221

Received 7th July 2017

Accepted 25th September 2017

DOI: 10.1039/c7ra07476j

rsc.li/rsc-advances

\title{
A shape memory polyurethane based ionic polymer-carbon nanotube composite
}

\author{
Huiqin Lian, ${ }^{\text {a }}$ Wei Chang, (D) ab Qian Liang, ${ }^{\text {ab }}$ Chufeng Hu, ${ }^{a}$ Rui Wang, ${ }^{a}$ Lei Zu ${ }^{a}$ \\ and Yang Liu ${ }^{a}$
}

\begin{abstract}
We report for the first time the fabrication of ionic polyurethane (IPU) based ionic polymer-carbon nanotube composite (IPCC) actuators. Graphene oxide (GO) was homogeneously dispersed in the IPU matrix to enhance the shape memory effect (SME) and action in terms of blocking force and displacement. Carbon nanotubes (CNTs) were used as the electrodes of the IPCC through a coating method. The blocking force of $25 \% \mathrm{GO}-\mathrm{IPU}$ was $7.8 \mathrm{gf} \mathrm{g}^{-1}$, it was 5 times that of neat IPU. Moreover, the shape memory recovery speed of the GO-IPU based IPCC was improved, from $3.2^{\circ} \mathrm{s}^{-1}$ for neat IPU to $4.5^{\circ} \mathrm{s}^{-1}$ for the composite membrane of $25 \% \mathrm{GO}-\mathrm{IPU}$. The results indicated that the novel actuator showed both shape memory performance and electromechanical behavior and GO enhanced the functional properties in terms of SME and actuation.
\end{abstract}

\section{Introduction}

Shape-memory polymers (SMPs) are smart materials which can respond to external stimuli such as light, electricity, $\mathrm{pH}$, temperature, chemical substances, and magnetism. ${ }^{1-3}$ SMPs have the virtues of low density, low cost, easy processing and biodegradability, ${ }^{\mathbf{4}, 5}$ all of which will benefit their application in the fields of textiles, ${ }^{6}$ coatings, ${ }^{7}$ packaging materials ${ }^{8}$ and so on.

Various polymers exhibit the shape memory effect (SME), including polyethene, polynorbornene, trans-polyisoprene and polyurethane. ${ }^{9}$ Among them, polyurethane has the advantages of biocompatibility ${ }^{\mathbf{1 0}}$ and structural diversity, and it has potential application in the fields of biomedicine ${ }^{\mathbf{1 1 , 1 2}}$ and aerospace. $^{\mathbf{1 1 , 1 2}}$

In general, a shape memory PU consists of a soft segment and a hard segment ${ }^{13}$ which shows thermal sensitivity. The typical SME mechanism of PU is that the PU film changes to a temporary state at a certain temperature, followed by a decrease in temperature to fix the temporary shape. The deformed PU film will recover back under high temperature. ${ }^{\mathbf{1 4 , 1 5}}$ Usually, the shape of PU displays three states only, which limits its application, especially in complex biosystems.

Electroactive materials ionic polymer-carbon nanotube composite (IPCC) has outstanding advantage of large displacement under low potential (1-5 V) stimuli. ${ }^{16-18}$ Combing IPCC with SME, SMP based IPCC will enhance the multifunction, thus its application becomes wide.

${ }^{a}$ Beijing Key Lab of Special Elastomer Composite Materials, College of Materials Science and Engineering, Beijing Institute of Petrochemical Technology, Beijing 102617, China. E-mail: lianhuiqin@bipt.edu.cn; Tel: +86-10-8129-2129

${ }^{b}$ College of Materials Science and Engineering, Beijing University of Chemical Technology, Beijing 100029, China
However, it is noticed that pure polymer based SMP and IPCC show relatively low force which is generated from the deformation of SMP and IPCC. It is well known that graphene oxide (GO) has a typical pseudo-two-dimensional structure that can provide reinforcement to the base polymer matrix. ${ }^{19}$ As a multifunctional filler, GO would enhance the rubber elasticity and strain recovery, which are important properties for shape memory materials. ${ }^{20} \mathrm{Li}$ et $a l .{ }^{21}$ reported that GO can enhance the SMP of PU. Moreover, Lian et $a .^{22}$ reported that the blocking force of GO-Nafion composite increased 3 time by doping GO. For IPCC system, GO improved the durability of actuator due to the lamellar-structured GO inhibited the liquid evaporation in IPCC resulting in a durable actuation. ${ }^{23}$ Generally, noble metals are used for IPCC electrodes through a tedious process. ${ }^{24}$ Carbon nanotube (CNT) shows amazing electrical properties due to the continuous and super-aligned structure of the CNT conductive network. ${ }^{25-27}$ Moreover, CNT shows good compatibility with polymer in composites. It is a good candidate for electrodes using in polymer based actuator.

In this study, shape memory PU based IPCC was fabricated with CNT electrodes. PU has the virtues of low-cost, easy preparation, environment-friendly and excellent shape memory property. GO filler was used to enhance the shape memory properties as well as the actuation performance in PU based IPCC. The novel multiple functional material will be used in high-tech fields in terms of biomedical as well as soft robot.

\section{Experimental section}

\subsection{Materials}

4,4'-Methylenediphenyl diisocyanate (MDI), 2,2-dimethylol propionic acid (DMPA), polytetramethylene ether glycol (PTMG, 
$M_{\mathrm{n}}=1000,99 \mathrm{wt} \%$ ) and carbon nanotube (CNT) were supplied by Aladdin-reagent Inc. PTMG was dehydrated at $100{ }^{\circ} \mathrm{C}$ under vacuum for 1 hour. $N, N$-Dimethylformamide (DMF, $99.9 \mathrm{wt} \%$ purity) was dried with $\mathrm{CaH}_{2}$ and distilled under reduced pressure prior to use. Graphene oxide (GO) was prepared from natural graphite flake using the modified Hummers' method. ${ }^{28}$ Other chemicals were used as received.

\subsection{Synthesis of ionic polyurethane (IPU)}

The route for synthesis of IPU was shown in Fig. 1. The mixture of $1.0 \mathrm{mmol}$ PTMG1000 and $9.9 \mathrm{mmol}$ MDI was heated at $85{ }^{\circ} \mathrm{C}$ with stirring under nitrogen for $2 \mathrm{~h}$ to form NCO-terminated prepolymer. Then, $8.9 \mathrm{mmol}$ DMPA in DMF (5 wt\%) was added to the reactor and the mixture was kept for $2 \mathrm{~h}$ under the reacting condition as mentioned above. The production was poured into deionized water, washed and dried at $80^{\circ} \mathrm{C}$ for $24 \mathrm{~h}$.

\subsection{Preparation of GO-IPU composite films}

The typical fabrication process of GO-IPU film was described below. $0.95 \mathrm{~g}$ IPU and $0.05 \mathrm{~g}$ GO were dispersed into $10 \mathrm{~mL}$ DMF. The mixture was sonicated in an ultrasonic for $1 \mathrm{~h}$, then stirred at $45{ }^{\circ} \mathrm{C}$ for $24 \mathrm{~h}$. The obtained solution was casted into the Teflon mold and dried for $24 \mathrm{~h}$ at $80{ }^{\circ} \mathrm{C}$ in a vacuum oven. Then, the thickness of composite film with GO content of $5 \mathrm{wt} \%$ was about $0.15 \mathrm{~mm}$, named 5\% GO-IPU. Using the procedure above, composite films of 15\% GO-IPU and 25\% GO-IPU were prepared.

\subsection{Fabrication of ionic polymer-carbon nanotube composite (IPCC)}

The electrode dispersion solution was composed by $20 \mathrm{wt} \%$ of CNTs, $20 \mathrm{wt} \%$ of IPU and $60 \mathrm{wt} \%$ of DMF. The mixture was first stirred at room temperature for $24 \mathrm{~h}$, then sonicated in an ultrasonic for $1 \mathrm{~h}$.

The GO-IPU films were activated in $1 \mathrm{M} \mathrm{H}_{2} \mathrm{SO}_{4}$ at $60{ }^{\circ} \mathrm{C}$ for $1 \mathrm{~h}$. Electrodes were fabricated by dipping coating method, i.e. IPU film was first dipped into electrode dispersion, then drew
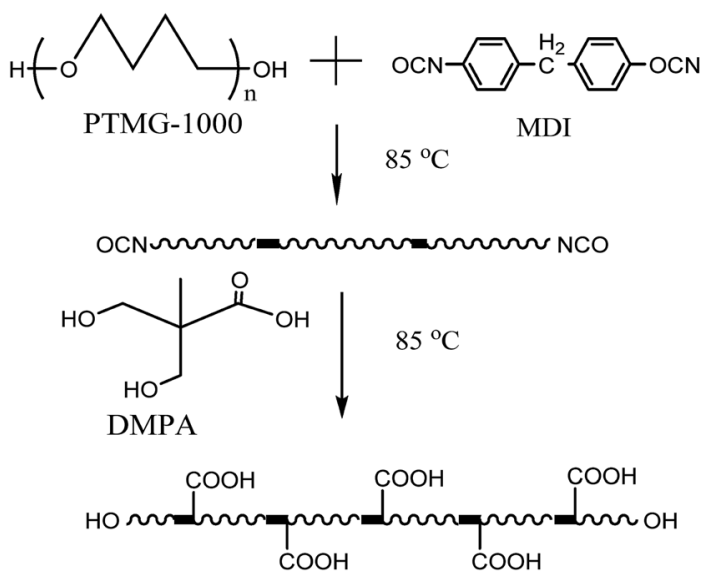

Fig. 1 General reaction scheme for the synthesis of IPU. out and dried at $70{ }^{\circ} \mathrm{C}$ for $20 \mathrm{~min}$. This procedure was repeated three times.

The resulting films were treated with $1 \mathrm{M} \mathrm{LiCl}$ solution at room temperature for $24 \mathrm{~h}$.

\subsection{Characterization}

FT-IR analysis was obtained using Nicolet 6700 spectrometer in the range of $400-4000 \mathrm{~cm}^{-1}$.

Differential scanning calorimetry (DSC) was performed in a range from -50 to $250{ }^{\circ} \mathrm{C}$. The scans was performed at a heating and cooling rate of $10{ }^{\circ} \mathrm{C} \mathrm{min}^{-1}$ in a nitrogen atmosphere (flow $=40 \mathrm{~mL} \min ^{-1}$ ).

Raman spectrum was performed with a Renishaw RM2000 confocal Raman spectrometer (RENISHAW, London, UK) with a $514 \mathrm{~nm}$ excitation laser.

X-ray diffraction (XRD was performed with Scintag PAD X diffractometer, $\mathrm{Cu} \mathrm{KR}$ source, operated at $45 \mathrm{kV}$ and $40 \mathrm{~mA}$ ).

Scanning electron microscopy (SEM) was performed with Tecnai T12.

Water uptake (W\%) was calculated using eqn (1):

$$
W \%=\frac{\left(W_{1}-W_{0}\right)}{W_{0}}
$$

$W_{1}$ and $W_{0}$ stand for the weights of the swollen and dried samples, respectively. In the beginning, a sandwich film was dried in vacuum condition at $80^{\circ} \mathrm{C}$ for $24 \mathrm{~h}$. Afterwards, the film will be soaked in deionized water at normal temperature for $24 \mathrm{~h}$. After this, the film was retrieved and the water on its surface was wiped off with the help of filter paper. Then it should be weighed instantly. What follows is to dry the film at $60{ }^{\circ} \mathrm{C}$ within vacuum condition and this process stops when the weight became constant.

The ion exchange capacity (IEC) was determined by placing the film in $1 \mathrm{~mol} \mathrm{~L}^{-1} \mathrm{NaCl}$ solution at $40{ }^{\circ} \mathrm{C}$ for $24 \mathrm{~h}$ followed by titration using a $0.01 \mathrm{~mol} \mathrm{~L}^{-1} \mathrm{NaOH}$ solution with phenolphthalein as an indicator. The ion exchange capacity (IEC, meq $\mathrm{g}^{-1}$ ) was calculated based on the dry weight of the sandwich film.

Proton conductivity was measured using a Keysight E4990A analyzer over the frequency range of $100 \mathrm{kHz}$ to $10 \mathrm{mHz}$ at a voltage of $1 \mathrm{~V}$. The measurement of all samples at room temperature. Proton conductivity was calculated by eqn (2):

$$
\sigma=\frac{d}{s R}
$$

while $d$ stand for the thickness of film, $s$ represent the area of the copper electrodes, and $R$ is the measured resistance of the film.

Characterization of the shape memory performance was carried out using a digital camera. All the IPCC samples were tested in $1 \mathrm{M}$ LiCl solution. First, the rectangular IPCC strip samples were bent to $135^{\circ}\left(\theta_{0}\right)$ at $85^{\circ} \mathrm{C}$ and the temperature was decreased to $0{ }^{\circ} \mathrm{C}$ to obtain the temporary shape. The angle between the both ends was recorded as $\theta_{\mathrm{f}}$; then IPCC samples were put into $85^{\circ} \mathrm{C} \mathrm{LiCl}$ solution to the recovery state with angle of $\theta_{\mathrm{r}}$. The shape fixity $\left(R_{\mathrm{f}}\right)$ and shape recovery ratio $\left(R_{\mathrm{r}}\right)$ were calculated according to eqn (3) and (4). 


$$
\begin{aligned}
& R_{\mathrm{f}} \%=\frac{\theta_{0}-\theta_{\mathrm{f}}}{\theta_{0}} \times 100 \\
& R_{\mathrm{r}} \%=\frac{\theta_{\mathrm{r}}-\theta_{0}}{\theta_{0}} \times 100
\end{aligned}
$$

Characterization of the actuation performance was carried out using a Labview-based system device. A programmable power, generated an electrical signal with periods of $1 \mathrm{~s}$ to 5 min, voltage of \pm 1.25 to $\pm 5 \mathrm{~V}$, and square wave. A balance with a sensitivity of $0.1 \mathrm{mg}$ was used to collect data through RS232 using Labview. All the IPCC samples were cut into $25 \mathrm{~mm} \times$ $5 \mathrm{~mm}$ rectangles, including the $5 \mathrm{~mm}$ of the electrode contact area. One end of the IPCC strip was fixed between two $\mathrm{Cu}$ electrodes. Displacement of the IPCCs under different electrical stimuli was captured by a laser displacement meter (LMI Technologies Inc Gocator 2130A-2M-R-01-T). All measurements were carried out in air at room temperature.

\section{Results and discussion}

\section{$3.1 \quad$ FT-IR}

The FTIR spectrum for IPU sample was shown in Fig. 2. The broad band at $3320 \mathrm{~cm}^{-1}$ was attributed to the $\mathrm{N}-\mathrm{H}$ stretching vibration. The bands centered at $1730 \mathrm{~cm}^{-1}$ and $1103 \mathrm{~cm}^{-1}$ were due to the $\mathrm{C}=\mathrm{O}$ and $\mathrm{C}-\mathrm{O}-\mathrm{C}$, respectively. ${ }^{29}$ And the absence of NCO groups at $2250-2279 \mathrm{~cm}^{-1}$ indicated that the reaction proceeded until complete conversion of the isocyanate. ${ }^{30}$ Therefore, the PU containing carboxylic acid group was synthesized successfully.

\subsection{DSC characterization}

The thermal behaviour of IPU was determined by DSC as shown in Fig. 3. IPU consisted of soft segment and hard segment with polyglycol as the soft segment and diisocyanate as the hard segment. The glass transition temperature $\left(T_{\mathrm{g}}\right)$ of IPU was

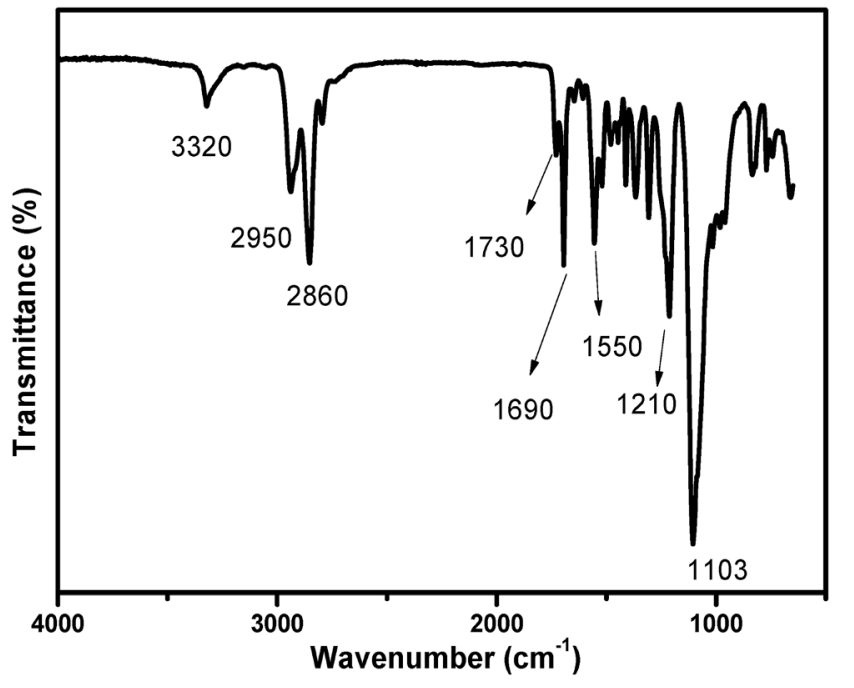

Fig. 2 FTIR spectrum of IPU.

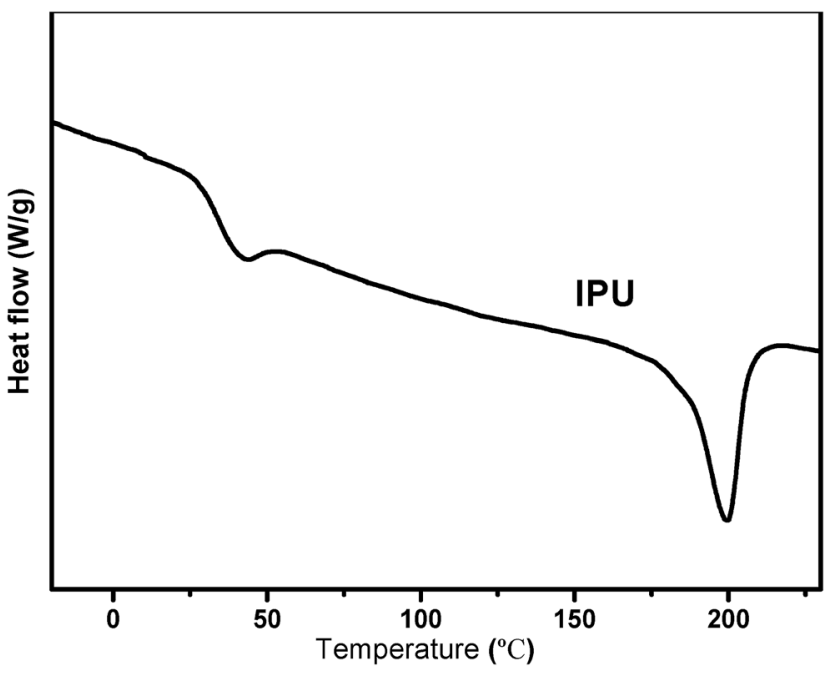

Fig. 3 DSC curve of IPU.

observed at about $43.5{ }^{\circ} \mathrm{C}$ and the melting temperature $\left(T_{\mathrm{m}}\right)$ of 199.7 ${ }^{\circ} \mathrm{C}$, which can be attributed to the hard phase. The results were comparable with that of PU reported by Lin. ${ }^{31}$

\subsection{Raman spectrum}

Raman was used to identify graphite and disorder GO, as shown in Fig. 4. From the Raman spectrum of GO powder, the band around $1350 \mathrm{~cm}^{-1}$ was attributed to D-band $\left(I_{\mathrm{D}}\right)$ caused by the defects and disorders in the hexagonal graphitic layers. The Gband $\left(I_{\mathrm{G}}\right)$ was around $1581 \mathrm{~cm}^{-1}$ related to the vibration of $\mathrm{sp}^{2}$ bonded carbon atoms in a two-dimensional hexagonal lattice. ${ }^{32}$ While for graphite, the $I_{\mathrm{G}}$ was much stronger than that of $I_{\mathrm{D}}$. The $I_{\mathrm{D}} / I_{\mathrm{G}}$ ratio of graphite was 0.09 , much lower than that of GO of 0.93. This demonstrated that GO showed a disorder state which benefited its dispersion in ionic polymer matrix. ${ }^{21}$

\subsection{XRD characterization}

The XRD patterns of GO-IPU membranes with different doping levels were presented in Fig. 5. IPU and GO-IPU composite film showed similar patterns with the broad peak of $2 \theta$ around $20.5^{\circ}$, which was attributed to the amorphous of IPU. ${ }^{33}$ This amorphous structure was similar with that of ionic polyurethane urean reported by Fuensanta. ${ }^{34}$ GO showed a strong peak of $2 \theta$ of $10.9^{\circ}$, which indicates the basal spacing of $0.90 \mathrm{~nm}$ of GO. ${ }^{35}$ The diffraction peak ascribed to GO did not appear in all of the XRD patterns, indicating the complete exfoliation of the GO in IPU. ${ }^{22}$ The exfoliated state was consisted with the disorder structure of Raman result as mentioned above.

\subsection{SEM observation}

Fig. 6 showed the SEM images of neat IPU and the 15\% GO-IPU film with CNT electrodes. The neat IPU showed a smooth fracture surface (Fig. 6A), while the GO-IPU composite film appeared a rough surface (Fig. 6B), which may resulted from the doping of the GO sheets in IPU. It can been seen that GO dispersed in IPU matrix uniformly, which was consistent with 


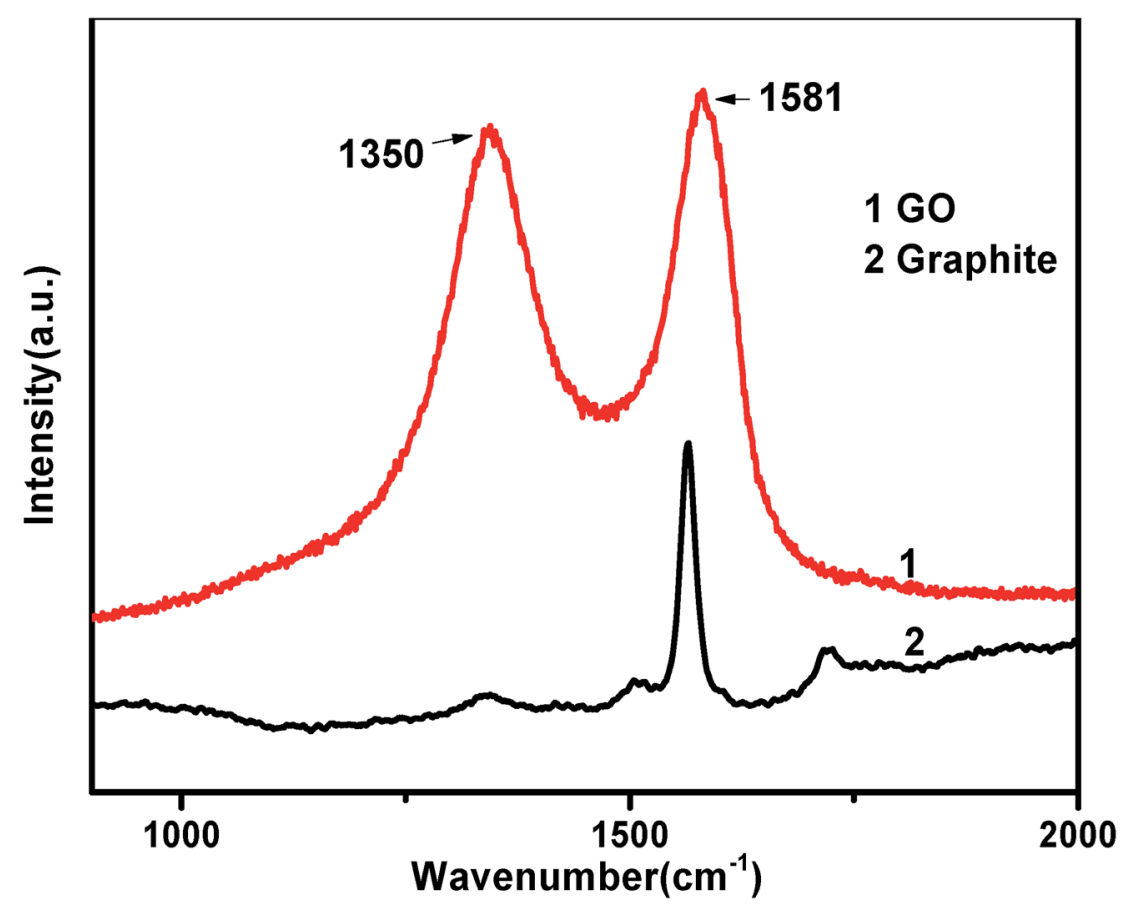

Fig. 4 Raman spectra of GO and graphite powder.

the result of XRD and Raman. The SEM images of composite membrane with CNT as electrodes were shown in Fig. 6C and D. The horizontal surface of the CNT electrodes (Fig. 6C) indicated that the surface of CNT electrodes was relatively uniform. It can be clearly seen from the cross-section (Fig. 6D) that the thickness of the CNT electrodes layer was about $80 \mu \mathrm{m}$ and was perfectly bonded with middle IPU membrane.

\subsection{Physical properties}

The physical properties of neat IPU and GO-IPU composite membranes was provided in Table 1 . When the content of GO was $25 \mathrm{wt} \%$, the composite membrane exhibited water uptake (WUP) of $25.41 \%$ and ion exchange capacity (IEC) of $0.52 \mathrm{meq}$

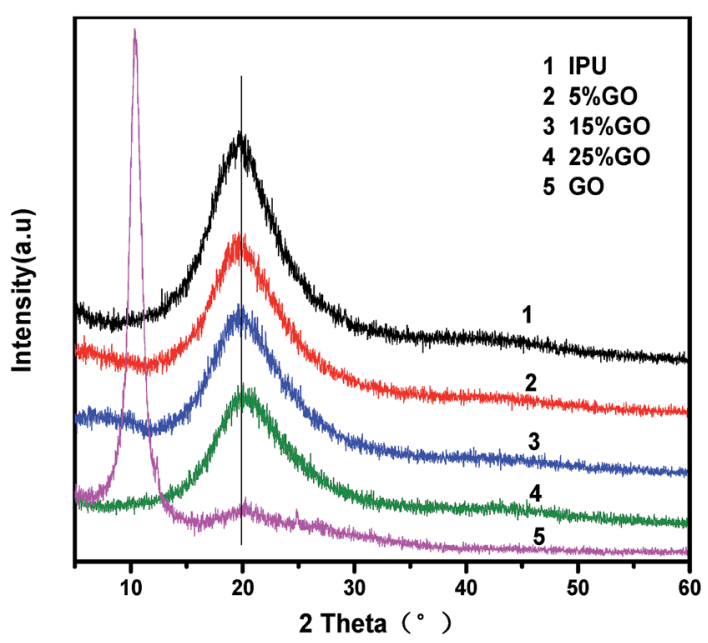

Fig. 5 XRD patterns of GO and GO-IPU composites. $\mathrm{g}^{-1}$. The corresponding values for the pure IPU were $15.38 \%$ and $0.44 \mathrm{meq}^{-1}$, respectively. It was noticed that WUP and IEC values of GO-IPU increased with GO content increase. It is reported that presence of nano filler could affect the size of polar clusters and the distribution of water domains in polar cages and the interconnected channels. ${ }^{36}$ The size of the cluster of ions and the number of exchange sites per cluster increase with the increase of the GO and thus result in an increase in water uptake and IEC.

The electrical conductivity of the membrane was one of the important parameters affecting the actuator performance, relationship between the conductivity of GO-IPU membrane and GO content was also shown in Table 1 . The conductivity of pure IPU was only $3.04 \times 10^{-8} \mathrm{~S} \mathrm{~cm}^{-1}$, whereas those of the GOIPU membranes were evidently increased with the increase in the doping levels of GO from $3.04 \times 10^{-8}$ to $1.60 \times 10^{-6} \mathrm{~S} \mathrm{~cm}^{-1}$. It indicated that height conductive nano-filler could improve conductivity polymer film. ${ }^{22}$

Fig. 7 showed the cyclic voltammetry response of CNT electrodes in a $1 \mathrm{M} \mathrm{KOH}$ basic solution at a sweep rate of $100 \mathrm{mV} \mathrm{s}^{-1}$. CNT electrodes cells appeared rectangular shape of voltammograms with a good symmetry. No redox peak observed demonstrated that CNT electrodes cells had good reversibility and capacitance characteristics. It indicated that the electric double layer charging/discharging was efficient in case of CNT electrodes based cell. ${ }^{37}$ Therefore, CNT was suitable for the electrode of ionic polymer actuator because it had a large volumetric capacitance and high electric double layer capacitances.

\subsection{Actuation property}

The actuator performance of the as-prepared GO-IPU sandwich membranes was measured by a cantilevered actuation system. ${ }^{22}$ 


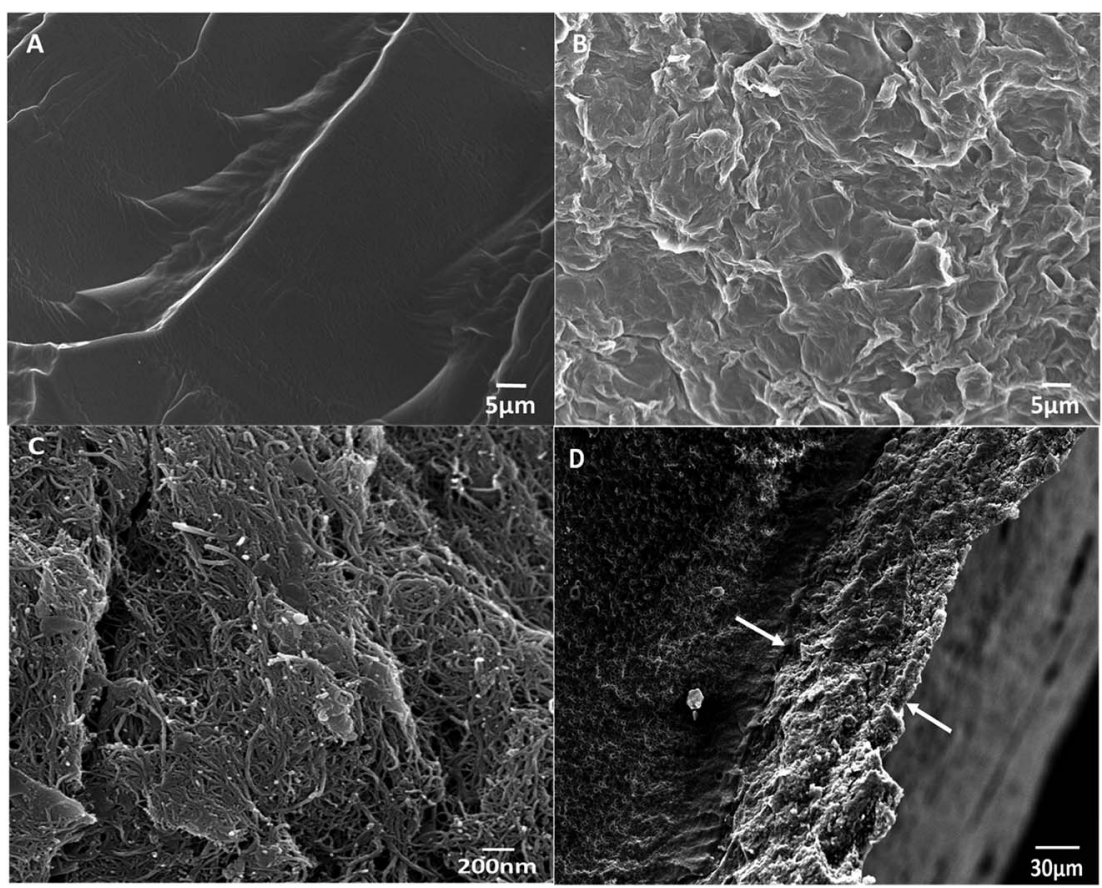

Fig. 6 Cross-section SEM images of (A) IPU; (B) 15 wt\% GO-IPU composite film; composite membrane with CNT as electrodes of (C) horizontal surface; (D) cross-section.

Table 1 Physical properties of neat IPU and GO-IPU sandwich films

\begin{tabular}{lllll}
\hline Film & $\begin{array}{l}\text { Water uptake } \\
(\%)\end{array}$ & $\begin{array}{l}\text { Swelling } \\
(\%)\end{array}$ & $\begin{array}{l}\text { IEC } \\
\left(\mathrm{meq} \mathrm{g}^{-1}\right)\end{array}$ & $\begin{array}{l}\text { Conductivity } \\
\left(\mathrm{S} \mathrm{cm}^{-1}\right)\end{array}$ \\
\hline Pure IPU & 15.38 & 3.24 & 0.44 & $3.04 \times 10^{-8}$ \\
$5 \%$ GO & 19.05 & 3.50 & 0.45 & $1.61 \times 10^{-7}$ \\
$15 \%$ GO & 22.32 & 4.07 & 0.48 & $4.71 \times 10^{-7}$ \\
$25 \%$ GO & 25.41 & 4.80 & 0.52 & $1.60 \times 10^{-6}$
\end{tabular}

The blocking force was defined as the force produced by one gram of IPCC actuator under a certain electric field. One end was fixed in the apparatus and the other end was fixed on

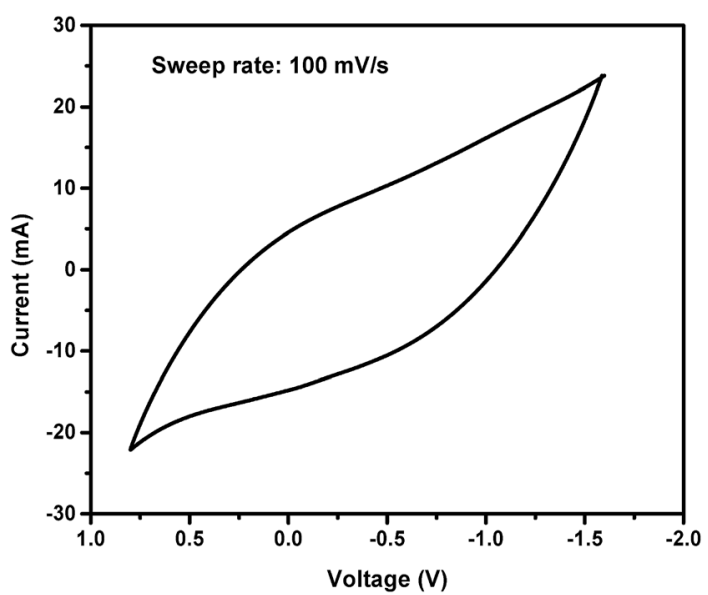

Fig. 7 Cyclic voltammetry response of CNT electrodes in a $1 \mathrm{M} \mathrm{KOH}$ basic solution at a sweep rate of $100 \mathrm{mV} \mathrm{s}^{-1}$. a balance. The GO-IPU IPCC actuators with different amount of GO under a voltage of $3 \mathrm{~V}$ with a period of $10 \mathrm{~s}$ were shown in Fig. 8. Pure IPU based IPCC showed blocking force of $1.54 \mathrm{gf}^{-1}$, while all of GO-IPU composites showed higher value than that of IPU. Furthermore, the blocking force of composite membrane increased monotonically with the increase of GO concentration. Moreover, 25\% GO-IPU IPCC exhibited the highest value of $7.8 \mathrm{gf} \mathrm{g}^{-1}$, about 5 times that of pure IPU, which was higher than that of 3 times reported by Lian. ${ }^{37}$ We supposed that GO increased the physical properties of composites in terms of WU, swelling and IEC, which enhance the degree of transmission of ion and its solvent-ion resulting the enhanced blocking force.

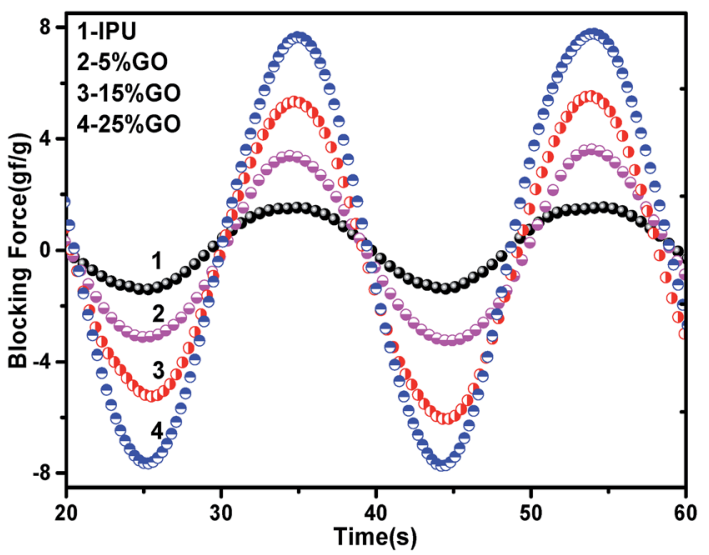

Fig. 8 The blocking force of IPCC actuators based on the pure IPU and the composite membranes under voltage $3 \mathrm{~V}$ with a period $10 \mathrm{~s}$. 

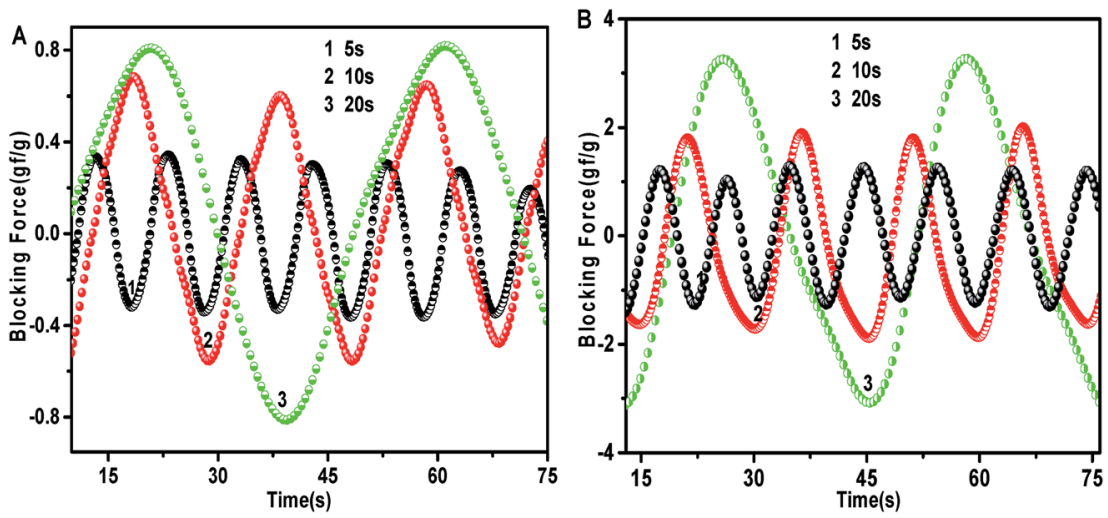

Fig. 9 The blocking force of IPCC actuators based on the pure IPU (A) and 25\% GO-IPU membrane (B) under $2 \mathrm{~V}$ with periods of $5 \mathrm{~s}, 10 \mathrm{~s}, 20 \mathrm{~s}$.

The relationship of IPCCs between driving time and blocking force was tested, as shown in Fig. 9. It can be seen that with the increase of driving period of time, from $5 \mathrm{~s}$ to $20 \mathrm{~s}$, the blocking forces of pure IPU based IPCC increased, from $0.35 \mathrm{gf}^{-1}$ to $0.83 \mathrm{gf}^{-1}$ as shown in Fig. 9A. Same trend was observed in $25 \%$ GO-IPU based IPCC (Fig. 9B). The results were consistent with the description in ref. 37.

Furthermore, the GO-IPU membrane showed higher blocking force than that of pure IPU under same testing condition. The value of blocking force of $25 \%$ GO-IPU based IPCC was 3.3 $\mathrm{gf}^{-1}$ under signal of voltage 2 period $20 \mathrm{~s}$, it was 4 times that of neat IPU based IPCC.

Displacements of GO-IPU composite based IPCC were measured as shown in Fig. 10. A point on IPCC with the distance $20 \mathrm{~mm}$ to fixed $\mathrm{Cu}$ electrode was chosen to measure the motion under a voltage of $3 \mathrm{~V}$ with a period of $10 \mathrm{~s}$. It could be seen that the value of displacement increased with the content of GO increase. Obviously, the membrane containing $25 \mathrm{wt} \%$ GO exhibited the largest displacement value of $2.2 \mathrm{~mm}$, larger than that of neat IPU of $0.36 \mathrm{~mm}$. According to the actuation mechanism of IPCC, the transmission of cation caused the displacement. The larger displacement of composite may be due to its higher ionic conductivity, according to the data listed in Table 1.

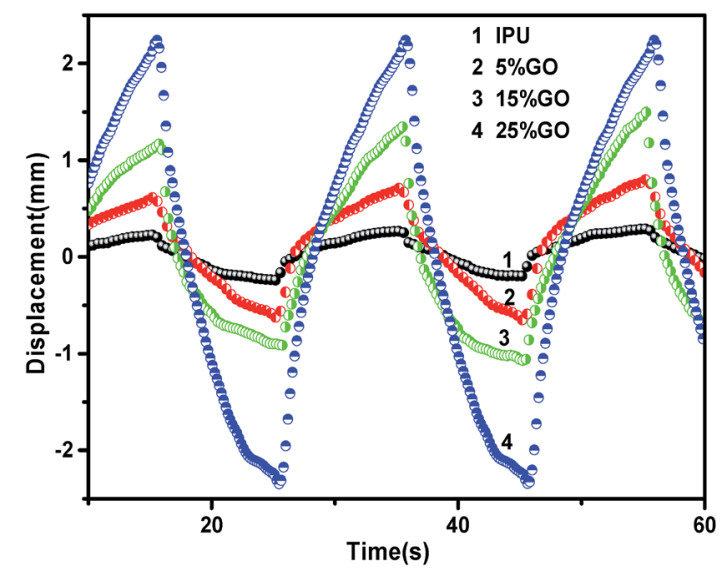

Fig. 10 Displacement of IPCC actuators based on the pure IPU and the composite membranes under voltage $3 \mathrm{~V}$ with a period $10 \mathrm{~s}$.
The strain $(\varepsilon)$ of membranes was calculate by the tip displacement. ${ }^{38}$ As shown in Fig. 11, pure IPU showed the least strain value of $0.09 \%$. It can be seen that the strain values of GO-IPU composites increased with the increase of GO content. The sample of $25 \%$ GO-IPU showed the highest value of $0.37 \%$. The result was comparable with that of Nafion based IPMC. ${ }^{22}$

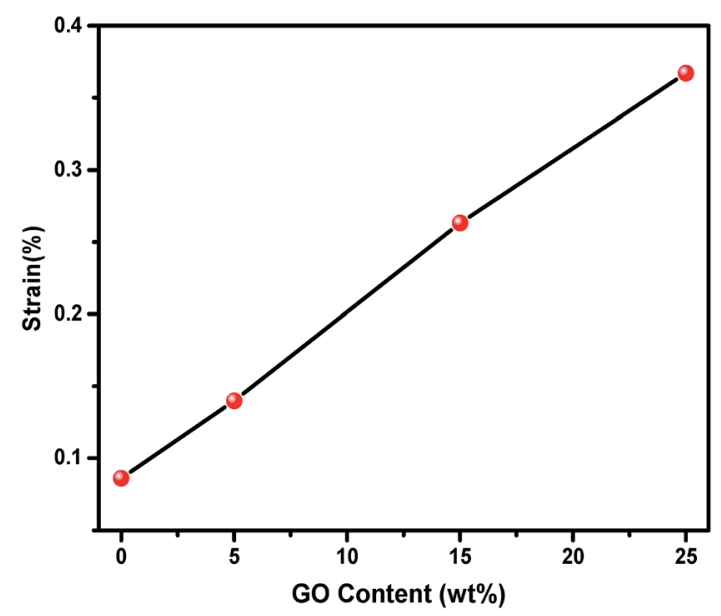

Fig. 11 Dependence of the generated strain $(\varepsilon)$ on the GO content of the membranes.

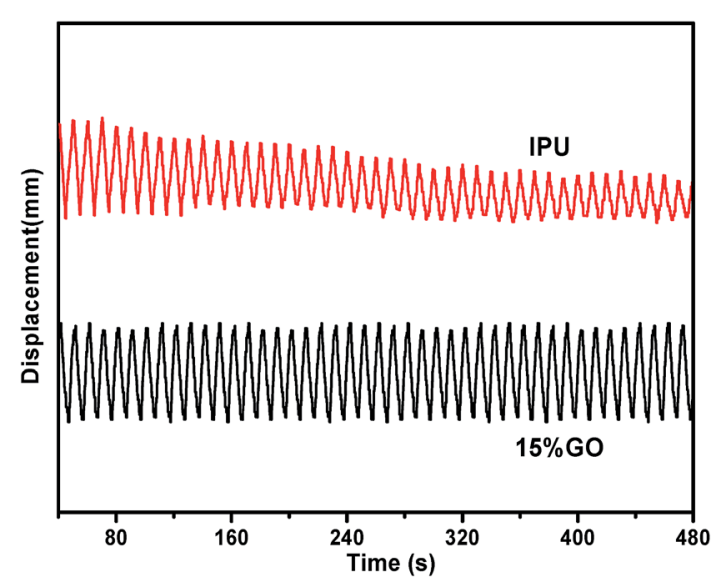

Fig. 12 Durability of pure IPU and 15\% GO composite film. 


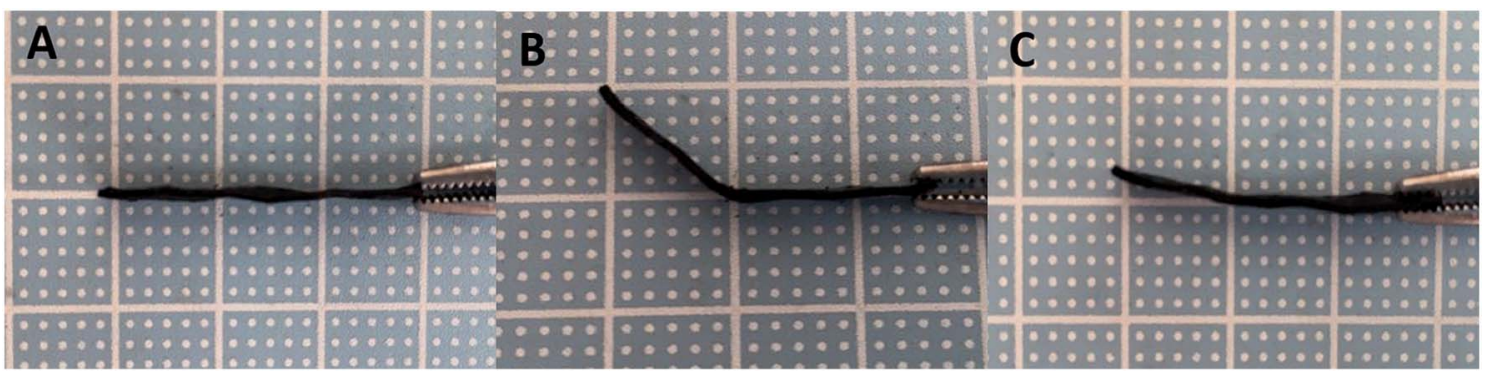

Fig. 13 Shape memory effect photos of $15 \%$ GO-IPU film, (A) the original state; (B) the temporary state; (C) the recovery state.

Durability of pure IPU and GO composite film was shown in Fig. 12. The difference value between the maximum and the minimum displacement in cycles of IPU actuator showed great decrease as time went on. However, GO-IPU actuator did not show visible decrease in displacement with increasing time. GO protected the inter-lamellar liquid from evaporation thus ensured the durability GO enhances the durability of IPU composites. $^{37}$

Table 2 Shape fixity and shape recovery ratio of IPU and GO-IPU

\begin{tabular}{|c|c|c|c|c|c|c|c|c|}
\hline \multirow[b]{2}{*}{ Cycles } & \multicolumn{2}{|c|}{$\underline{\text { IPU }}$} & \multicolumn{2}{|c|}{$5 \%$ GO } & \multicolumn{2}{|c|}{$15 \%$ GO } & \multicolumn{2}{|c|}{$25 \%$ GO } \\
\hline & $R_{\mathrm{f}}$ & $R_{\mathrm{r}}$ & $R_{\mathrm{f}}$ & $R_{\mathrm{r}}$ & $R_{\mathrm{f}}$ & $R_{\mathrm{r}}$ & $R_{\mathrm{f}}$ & $R_{\mathrm{r}}$ \\
\hline 1 & 99 & 55 & 98 & 66 & 99 & 74 & 99 & 82 \\
\hline 2 & 99 & 54 & 99 & 66 & 98 & 73 & 98 & 82 \\
\hline 3 & 98 & 54 & 99 & 65 & 97 & 72 & 98 & 81 \\
\hline
\end{tabular}

Table 3 Average shape recovery speed of all the samples

\begin{tabular}{lllll}
\hline & IPU & $5 \%$ & $15 \%$ & $25 \%$ \\
Cycles & $\left({ }^{\circ} \mathrm{s}^{-1}\right)$ & $\mathrm{GO}\left({ }^{\circ} \mathrm{s}^{-1}\right)$ & $\mathrm{GO}\left({ }^{\circ} \mathrm{s}^{-1}\right)$ & $\mathrm{GO}\left({ }^{\circ} \mathrm{s}^{-1}\right)$ \\
\hline 1 & 3.2 & 3.7 & 4.0 & 4.5 \\
2 & 3.2 & 3.6 & 3.9 & 4.4 \\
3 & 3.1 & 3.5 & 3.9 & 4.3
\end{tabular}

\subsection{Shape memory property}

The shape memory effects of $15 \%$ GO-IPU based IPCC were shown in Fig. 13. The original state of IPCC film was shown in Fig. 13A. The rectangular IPCC strip samples were bent to $135^{\circ}$ at $85{ }^{\circ} \mathrm{C} 1 \mathrm{M} \mathrm{LiCl}$ and then deformation was kept at $0{ }^{\circ} \mathrm{C} \mathrm{LiCl}$ for 5 min to obtain the temporary state (Fig. 13B). The temporary state IPCC sample was recovered at $85{ }^{\circ} \mathrm{C} 1 \mathrm{M} \mathrm{LiCl}$ to get the recovery state (Fig. 13C). The shape fixity and shape recovery ratio of the IPU and GO-IPU composite films were listed in Table 2. The values of $R_{\mathrm{f}}$ for different samples were almost the same around $98 \%$. However, the $R_{\mathrm{r}}$ value varied significantly with the increase of GO content, from $R_{\mathrm{r}}$ of $55 \%$ of pure IPU increased to $82 \%$ of $25 \%$ GO IPU in the first cycle. Interesting, all the samples showed good durability in cycles, the values of $R_{\mathrm{r}}$ decreased slightly from $55 \%$ of the first cycle to $54 \%$ of the third cycle. Similarly, $R_{\mathrm{r}}$ values of GO-IPU composite films decreased slightly in cycles.

The shape memory recovery speed of samples was investigated, as listed in Table 3. It can be seen that the recovery of GO-IPU composite membrane increased with the GO content increase. The shape memory behavior was because of the phase change of polymer due to the temperature change. ${ }^{21}$ Therefore, comparing to pure IPU, the higher speed shape recovery response of GO-IPU composite was because of the high thermal conductivity of GO. ${ }^{39}$

In order to value the actuation of shape memory IPCC, the actuation of IPCC based on shape memory film in temporary
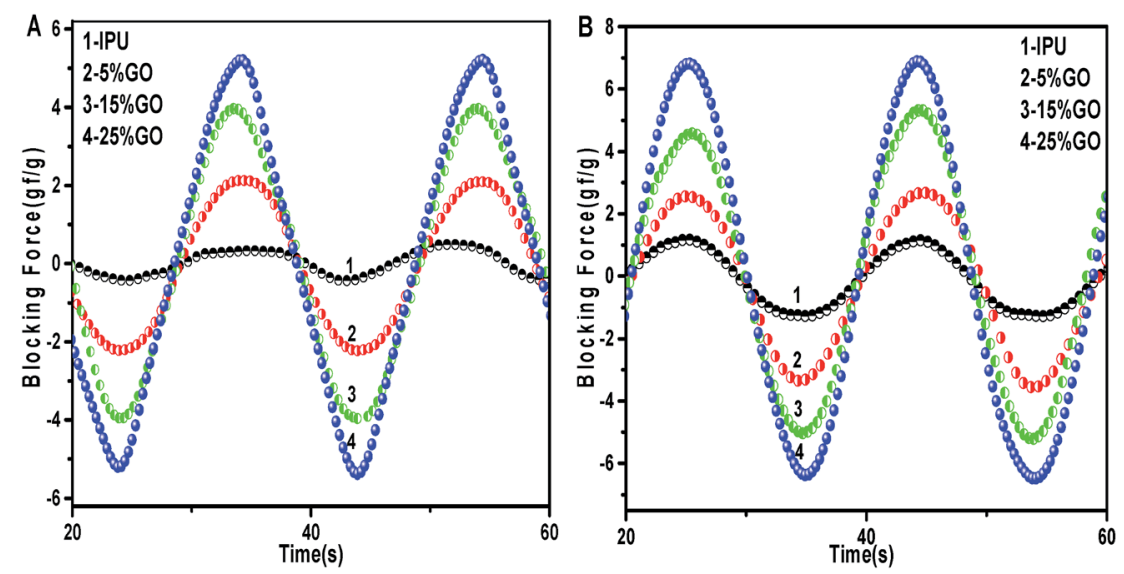

Fig. 14 The blocking force of IPCC actuators in the temporary state (A) and recovery state (B) under voltage $3 \mathrm{~V}$ with a period $10 \mathrm{~s}$. 
state and recovery state was investigated, as shown in Fig. 14 . Fig. 14A showed that the IPCCs in temporary state appeared normal actuation behavior. The blocking force of IPCC in temporary state increased with GO content increase, from $0.6 \mathrm{gf}$

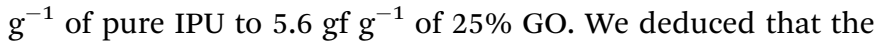
interaction between GO and IPU in matrix was strong enough to keep the actuation behavior in temporary state. The blocking fore of IPCC in recovery state was shown in Fig. 14B. The value of all samples were higher than the temporary state, and close to the initial state.

\section{Conclusion}

Novel IPCC actuators based on shape memory PU were fabricated using CNT electrodes which were obtained through coating. The actuator showed both shape memory behavior and electromechanical performance which enriched the actuation function of actuator. GO filler enhanced both shape memory effect and electromechanical property of PU in terms of the shape recovery speed, blocking force and displacement compared with that of pure IPU.

\section{Conflicts of interest}

There are no conflicts of interest to declare.

\section{Acknowledgements}

This work was supported by the Natural Science Foundation of China (NSFC, No. 51063009, 21271031, 51203012), the Beijing Natural Science Foundation of China (No. 2132009, 2122015), and the project about the promotion of innovation in Beijing universities funded by Beijing Municipal commission of education of China (TJSHG201510017024).

\section{References}

1 S. Gu, B. Yan, L. Liu and J. Ren, Eur. Polym. J., 2013, 49, 38673877.

2 J. Leng, X. Lan, Y. Liu and S. Du, Prog. Mater. Sci., 2011, 56, 1077-1135.

3 H. Wen, S. Chen, Z. Ge, H. Zhuo, J. Ling and Q. Liu, RSC Adv., 2017, 7, 31525-31534.

4 M. Raja, S. H. Ryu and A. M. Shanmugharaj, Colloids Surf., A, 2014, 450, 59-66.

5 B. Yan, S. Gu and Y. Zhang, Eur. Polym. J., 2013, 49, 366-378. 6 M. Behl and A. Lendlein, J. Mater. Chem., 2010, 20, 33353345.

7 J. W. Cho, C. J. Yong, B. C. Chun and Y. C. Chung, J. Appl. Polym. Sci., 2010, 92, 2812-2816.

8 M. Behl, M. Y. Razzaq and A. Lendlein, Adv. Mater., 2010, 22, 3388.

9 J. Hu, Y. Zhu, H. Huang and J. Lu, Prog. Polym. Sci., 2012, 37, 1720-1763.

10 A. C. Weems, J. E. Raymond, A. D. Easley, M. A. Wierzbicki, T. Gustafson, M. B. B. Monroe and D. J. Maitland, RSC Adv., 2017, 7, 19742-19753.
11 W. Wang, P. Ping, X. Chen and X. Jing, Eur. Polym. J., 2006, 42, 1240-1249.

12 Y. Xu and D. Chen, Mater. Chem. Phys., 2017, 195, 40-48.

13 J. T. Kim, B. K. Kim, E. Y. Kim, H. C. Park and H. M. Jeong, React. Funct. Polym., 2014, 74, 16-21.

14 Y. Zhang, W. Li, R. Wu and W. Wang, RSC Adv., 2017, 7, 33701-33707.

15 N. Mirtschin and T. Pretsch, RSC Adv., 2015, 5, 46307-46315.

16 B. J. Akle, M. D. Bennett and D. J. Leo, Sens. Actuators, A, 2006, 126, 173-181.

17 M. Shahinpoor, Y. Bar-Cohen, T. Xue, J. S. Harrison and J. Smith, Field Responsive Polymers, 1999, 726, 251-267.

18 H. Rasouli, L. Naji and M. G. Hosseini, RSC Adv., 2017, 7, 3190-3203.

19 S.-H. Kang, T.-H. Fang and Z.-H. Hong, J. Phys. Chem. Solids, 2013, 74, 1783-1793.

20 J. T. Kim, B. K. Kim, E. Y. Kim, H. C. Park and H. M. Jeong, React. Funct. Polym., 2014, 74, 16-21.

21 Y. Li, H. Lian, Y. Hu, W. Chang, X. Cui and Y. Liu, polymers, 2016, 8, 236.

22 Y. Lian, Y. Liu, T. Jiang, J. Shu, H. Lian and M. Cao, J. Phys. Chem. C, 2010, 114, 9659-9663.

23 Y. Hu, H. Lian, L. Zu, Y. Jiang, Z. Hu, Y. Li, S. Shen, X. Cui and Y. Liu, J. Mater. Sci., 2015, 51, 1376-1381.

24 M. Shahinpoor and K. J. Kim, Smart Mater. Struct., 2001, 10, 819-833.

25 L. Chen, C. Liu, K. Liu, C. Meng, C. Hu, J. Wang and S. Fan, ACS Nano, 2011, 5, 1588-1593.

26 V. N. Popov, Mater. Sci. Eng., R, 2004, 43, 61-102.

27 Y. Saito and S. Uemura, Carbon, 2000, 38, 169-182.

28 H. R. Pant, P. Pokharel, M. K. Joshi, S. Adhikari, J. K. Han, H. P. Chan and C. S. Kim, Chem. Eng. J., 2015, 270, 336-342.

29 X. Li, H. Deng, Z. Li, H. Xiu, X. Qi, Q. Zhang, K. Wang, F. Chen and Q. Fu, Composites, Part A, 2015, 68, 264-275.

30 S. M. Cakić, I. S. Ristić, M. Marinović-Cincović and M. Špírková, Int. J. Adhes. Adhes., 2013, 41, 132-139.

31 M. F. Lin, Y. C. Shu, W. C. Tsen and F. S. Chuang, Polym. Int., 2015, 48, 433-445.

32 J. Kim, J. H. Jeon, H. J. Kim, H. Lim and I. K. Oh, ACS Nano, 2014, 8, 2986-2997.

33 C. Wang, C. Ma, C. Mu and W. Lin, RSC Adv., 2017, 7, 2752227529.

34 M. Fuensanta, J. A. Jofre-Reche, F. Rodríguez-Llansola, V. Costa, J. I. Iglesias and J. M. Martín-Martínez, Prog. Org. Coat., 2017, 112, 141-152.

35 G. Z. Kyzas, D. N. Bikiaris and E. A. Deliyanni, Mater. Lett., 2014, 128, 46-49.

36 N. V. Di, R. Gliubizzi, E. Negro and G. Pace, J. Phys. Chem. B, 2006, 110, 24972-24986.

37 L. Zu, Y. Li, H. Lian, Y. Hu, W. Chang, B. Liu, Y. Liu, X. Ao, Q. Li and X. Cui, Macromol. Mater. Eng., 2016, 301, 10761083.

38 T. Sugino, K. Kiyohara, I. Takeuchi, K. Mukai and K. Asaka, Sens. Actuators, B, 2009, 141, 179-186.

39 H. Lian, S. Li, K. Liu, L. Xu, K. Wang and W. Guo, Polym. Eng. Sci., 2011, 51, 2254-2260. 